\title{
Relationship between plasma 25-hydroxyvitamin D and leucocyte telomere length by sex and race in a US studył
}

\author{
Jason J. Liu ${ }^{1} \dagger$, Elizabeth K. Cahoon ${ }^{1} \dagger$, Martha S. Linet ${ }^{1}$, Mark P. Little ${ }^{1}$, Casey L. Dagnall ${ }^{1,2}$, \\ Herbert Higson ${ }^{1,2}$, Sharon A. Savage ${ }^{1}$ and D. Michal Freedman ${ }^{1 *}$ \\ ${ }^{1}$ Division of Cancer Epidemiology and Genetics, National Cancer Institute, National Institutes of Health, Rockville, \\ MD 20850, USA \\ ${ }^{2}$ Cancer Genomics Research Laboratory, Leidos Biomedical Research, Inc., Frederick National Laboratory for Cancer \\ Research, Frederick, MD 21702, USA
}

(Submitted 19 August 2015 - Final revision received 8 April 2016 - Accepted 27 April 2016 - First published online 12 August 2016)

\section{Abstract}

A few studies have examined the association between vitamin D and telomere length, and fewer still have examined the relationship in black or male populations. We investigated the cross-sectional association between the vitamin D metabolite 25-hydroxyvitamin D (25(OH)D) concentration in plasma and relative leucocyte telomere length (LTL) in 1154 US radiologic technologists who were 48-93 years old (373 white females, 278 white males, 338 black females, 165 black males). Plasma 25(OH)D concentration was measured by the chemiluminescence immunoassay, and relative LTL was measured by quantitative PCR. Logistic regression was used to obtain OR and $95 \%$ CI for long $v$. short (based on median) LTL in relation to continuous $25(\mathrm{OH}) \mathrm{D}$, quartiles of $25(\mathrm{OH}) \mathrm{D}$ and $25(\mathrm{OH}) \mathrm{D}$ deficiency. We found no significant association between continuous 25(OH)D and long LTL in all participants $\left(P_{\text {trend }}=0.440\right)$, nor in white females $\left(P_{\text {trend }}=0.845\right)$, white males $\left(P_{\text {trend }}=0.636\right)$, black females $\left(P_{\text {trend }}=0.967\right)$ or black males $\left(P_{\text {trend }}=0.484\right)$. Vitamin $\mathrm{D}$ deficiency $(\mathrm{defined}$ as $25(\mathrm{OH}) \mathrm{D}<30 \mathrm{nmol} / \mathrm{l})$, however, was significantly associated with short LTL in whites $(P=0.024)$, but not in other groups. In this population, we found little evidence to support associations between $25(\mathrm{OH}) \mathrm{D}$ and long LTL over the entire range of $25(\mathrm{OH}) \mathrm{D}$ in the overall study population or by sex and race.

\section{Key words: Vitamin D: 25-Hydroxymitamin D: Leucocyte telomere length: Sexes: Race}

Vitamin D and telomere length have both been associated with various health outcomes, but there have been only a few studies on the relationship between them ${ }^{(1-4)}$. Vitamin $D$ is a hormone synthesised photochemically in the skin or ingested from foods and supplements that is subsequently hydroxylated in the liver to its major circulating form 25-hydroxyvitamin D (25(OH)D). Vitamin D deficiency has been associated with cancer and other chronic diseases, although whether those relationships are causal remains uncertain ${ }^{(5-7)}$. Vitamin D may also play a role in telomere biology by reducing cell proliferation $^{(6,7)}$ and inflammation ${ }^{(1,8)}$. Telomeres consist of nucleotide repeats and a protein complex at the ends of linear chromosomes that are essential for chromosomal integrity ${ }^{(9)}$. Telomeres naturally shorten with each cell division, and the shortening process can be accelerated by oxidative stress ${ }^{(10)}$. Thus, telomere length is considered to be a biomarker of cellular ageing and has been associated with disease risk and mortality ${ }^{(11,12)}$.

Previous studies on plasma 25(OH)D concentration (commonly regarded as a biomarker of vitamin $\mathrm{D}$ status) and leucocyte telomere length (LTL) have been largely limited to women and whites ${ }^{(1-3)}$; two studies of predominantly or exclusively white women found associations between lower 25(OH)D concentration and shorter leucocyte telomeres ${ }^{(1,2)}$. Another small study on women with systemic lupus erythematosus found no correlation between $25(\mathrm{OH}) \mathrm{D}$ baseline levels and $\mathrm{LTL}^{(3)}$. Recently, a study of white men found no association between vitamin D and $\mathrm{LTL}^{(4)}$, and another study on young individuals (all age 31 years), predominantly white men and women, also detected no relationship between them ${ }^{(13)}$. It is important to investigate whether the associations previously observed between $25(\mathrm{OH}) \mathrm{D}$ and LTL in white women can be replicated and are generalisable to other groups. To our knowledge, no study thus far has evaluated the relationship between 25(OH)D and LTL in a population with considerable proportions of men, women, blacks and whites, and none have examined effect modification of the relationship between $25(\mathrm{OH}) \mathrm{D}$ and LTL by sex and race.

The objective of this study was to assess the relationship between $25(\mathrm{OH}) \mathrm{D}$ and LTL using data from the US Radiologic

Abbreviations: 25(OH)D, 25-hydroxyvitamin D; LRT, likelihood ratio test; LTL, leucocyte telomere length; USRT, US Radiologic Technologists.

* Corresponding author: D. M. Freedman, fax +1240276 7874, email freedmam@mail.nih.gov

$\dagger$ These authors contributed equally to this work.

\$ The original version of this article was published with an incorrect spelling in the title. A notice detailing this has been published and the error rectified in the online and print PDF, and HTML copies. 
Technologists (USRT) study. This study includes 1154 participants with substantial proportions of women, men, blacks and whites with measurements of plasma $25(\mathrm{OH}) \mathrm{D}$ concentration, LTL and information on an extensive number of lifestyle factors

\section{Methods \\ Overview}

The USRT is an occupational cohort, which comprises radiologic technologists who were certified by the American Registry of Radiological Technologists for at least 2 years from 1926 through $1982^{(14)}$. Descriptions of the cohort and methods have been previously published ${ }^{(14,15)}$. In brief, detailed self-administered questionnaires were mailed to cohort members during three time periods - 1983-1989, 1994-1998 and 2003-2005 - to assess work history, lifestyle factors, reproductive, medical and family cancer history and a broad range of serious disease outcomes. The USRT study has been annually approved by human subjects review boards at the University of Minnesota and the National Cancer Institute. All participants of this study provided written informed consent.

\section{Study population}

The target population for this study included a sample of 10752 technologists chosen to represent the overall cohort. To this group, we added all black participants ( $n$ 2593) of the USRT study who were not part of the representative sample because black participants constitute only a small subset of the entire cohort (Fig. 1). Of these, only 9141 technologists from the representative sample and 2374 from the additional sample of black participants were eligible for the present study because they were alive and had not previously refused blood sample collections. We requested a blood sample and sent a mailed questionnaire between August 2008 and December 2009. Each month, random samples from the representative and black group were chosen within strata defined by sex, age $(<60$; $60+$ years) and ambient UV radiations (based on National Aeronautics and Space Museum (NASA) satellite data). A total of 4117 participants provided blood samples as requested. Owing to limited resources, 25(OH)D assays were performed on a subset of 1500 individuals (selected on the basis of a random stratified sample), including 842 white and 646 black participants and twelve participants identified as not white or black ${ }^{(16)}$. Of the 1488 samples from white and black participants, 1154 were successfully assayed for relative LTL (711 women, 443 men, 651 whites and 503 blacks), with an age range of 48-93 years.

\section{Outcome assessment}

Relative telomere length determination by quantitative PCR measures the ratio of telomere (T) signals, specific to the telomere hexamer repeat sequence TTAGGG, to autosomal singlecopy gene (S) signals. This ratio is normalised by control DNA samples to yield relative standardised T:S ratios proportional to the average telomere length. In this technique, reactions are performed independently, so a standard curve of pooled genomic DNA samples is utilised to assess the amount of each signal, while compensating for inter-plate variations in PCR efficiency. This telomere length measurement assay was adapted from the published method by Cawthon ${ }^{(17,18)}$.

Sample DNA of $4 \mathrm{ng}$, according to Quant-iT PicoGreen dsDNA quantitation (Life Technologies), was transferred into LightCycler-compatible 384-well plates (Roche) and dried down. An internal standard curve (six concentrations of pooled reference DNA samples spanning a ninety-seven.6-fold range in concentration, prepared by serial dilution) and randomly located internal quality control samples utilised as calibrator samples were applied to the assay plates to guide analysis and indicate the overall quality of assay performance. In addition, a no-template control was added to random wells of the 384-well plate to provide a unique fingerprint for each plate. All experimental and control samples were assayed in triplicate on each plate. PCR was performed using 5-ul reaction volumes consisting of 2.5 ul of 2X Rotor-Gene SYBR Green PCR Master Mix (QIAGEN), 2.0 ul of molecular biology-grade water and $0.5 \mathrm{ul}$ of $1 \mu \mathrm{M}$-assay-specific mix of primers. Oligonucleotides (Integrated DNA Technologies) were manufactured by LabReady by Integrated DNA Technologies (normalised to 100 $\mu \mathrm{m}$ in $1 \mathrm{X}$ Tris EDTA, pH 8.0 and HPLC purified). Primers for the telomeric PCR were Telo_FP (5'-CGGTTT(GTTTGG) 5 GTT-3') and Telo_RP (5'-GGCTTG(CCTTAC) 5 CCT-3' ${ }^{(19)}$. Primers for the single-copy gene (36B4) PCR were 36B4_FP (5'-CAGCAAGTG GGAAGGTGTAATCC-3') and 36B4_RP (5'-CCCATTCTATC ATCAACGGGTACAA- $\left.3^{\prime}\right)^{(17)} ; 1$ m-assay mixes were generated by combining $990 \mathrm{ul}$ of $1 \mathrm{X}$ Tris-EDTA buffer with $5 \mathrm{ul}$ of forward oligo and 5 ul of reverse oligo.

Thermal cycling was performed on a LightCycler 480 (Roche) where PCR conditions consisted of the following: cycling for $\mathrm{T}$ (telomeric) PCR $-95^{\circ} \mathrm{C}$ hold for $5 \mathrm{~min}$, denature at $98^{\circ} \mathrm{C}$ for $15 \mathrm{~s}$, anneal at $54^{\circ} \mathrm{C}$ for $2 \mathrm{~min}$, with fluorescence data collection, thirtyfive cycles; cycling for S (single-copy gene, $36 B 4$ ) PCR $-98^{\circ} \mathrm{C}$ hold for $5 \mathrm{~min}$, denature at $98^{\circ} \mathrm{C}$ for $15 \mathrm{~s}$, anneal at $58^{\circ} \mathrm{C}$ for $1 \mathrm{~min}$, with fluorescence data collection, forty-three cycles. LightCycler software (Release 1.5.0) was used for initial analysis of raw data. Utilising absolute quantification analysis with the second derivative maximum method and high-sensitivity detection algorithm, single target sequences were quantified and expressed as an absolute value (ng/ul) based on the internal standard curve of known concentrations. The concentration of telomere (T) signal was divided by the concentration of $36 B 4$ (S) signal to yield a T:S ratio. This raw T:S ratio was then divided by the average $\mathrm{T}: \mathrm{S}$ ratio of the internal quality control (QC) calibrator samples, within the same plate, to yield the final standardised $\mathrm{T}: \mathrm{S}$ ratio for the unknown sample. The inter-assay $\mathrm{CV}$, calculated using the internal QC calibrator samples ( $n$ 80), was $8.4 \%$ for the relative LTL assay.

\section{Exposure assessment}

Plasma 25(OH)D level was measured by Heartland Assays, Inc. using the LIAISON chemiluminescence immunoassay analyzer of DiaSorin. Heartland Assays, Inc. participated in the Vitamin D External Quality Assessment Scheme (DEQAS) proficiency testing scheme for the Liaison instrument; five quality control samples per batch were selected in a run-in to represent low, medium and 


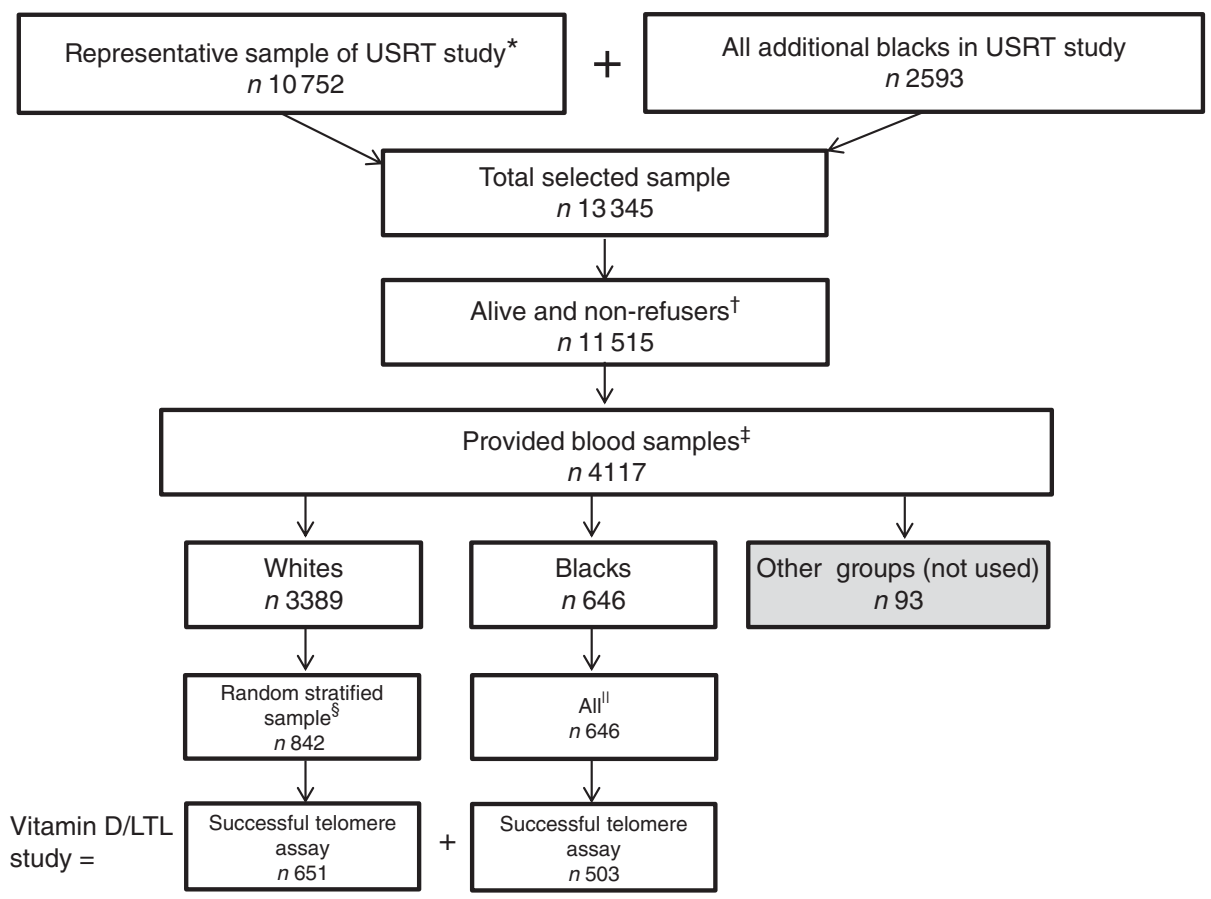

Fig. 1. Selection of 1154 subjects in the US Radiologic Technologists' (USRT) study of plasma 25-hydroxyvitamin D (25(OH)D) and relative leucocyte telomere length (LTL). * Derived from all racial/ethnic groups. $\dagger$ Had not previously refused blood sample collection. $\ddagger \leq 9 \mathrm{~d}$ between blood collection and questionnaire administration. $\S$ Randomly stratified sample based on sex, ambient UV radiations, age $(<60 ; 60+$ years) and season, with $25(\mathrm{OH}) \mathrm{D}$ measurements. $\|$ With $25(\mathrm{OH}) \mathrm{D}$ measurements.

high plasma $25(\mathrm{OH}) \mathrm{D}$ concentrations and these averaged $42 \cdot 1,69 \cdot 8$ and $101 \cdot 2 \mathrm{nmol} / \mathrm{l}$, respectively. Quality control samples were randomly distributed across and within batches. For low, medium and high plasma $25(\mathrm{OH}) \mathrm{D}$, the total CV were $8 \cdot 3,7 \cdot 2$ and $5 \cdot 8 \%$, respectively, with an overall average of $7 \cdot 1 \%$.

\section{Covariate assessment}

Information on potential confounders in this study population was ascertained from self-administered questionnaires, which were mailed to participants at the time of blood sample collection (2008-2009). These questionnaires collected information on current smoking status (yes/no), current weight, indoor physical activity levels in last $30 \mathrm{~d}$, use of vitamin D supplementation in the past $30 \mathrm{~d}$, menopausal status and use of menopausal hormone therapy (never, former, current). Estimated cumulative occupational ionising radiation dose to the red bone marrow was based on badge readings, work history and literature-based badge dose survey data and has been previously described in detail $^{(20)}$. For individuals who reported not being a current smoker, we used information from previously completed questionnaires to determine whether they were former smokers. For participants with missing information on weight ( $n$ 69), we used weight reported on the third USRT survey (2003-2005) to calculate BMI for fifty-eight individuals with available information.

\section{Statistical analyses}

To evaluate the relationship between plasma $25(\mathrm{OH}) \mathrm{D}$ concentration and LTL, logistic regression was used to compute OR and $95 \% \mathrm{CI}$ of long LTL in relation to plasma $25(\mathrm{OH}) \mathrm{D}$ concentration. Long LTL was defined as normalised T:S LTL values higher than the median in the total population (with the reference group representing participants with LTL values below the median). We examined the relationship of long LTL with continuous plasma $25(\mathrm{OH}) \mathrm{D}$ concentration, plasma 25 $(\mathrm{OH}) \mathrm{D}$ quartiles based on the total study population $(<45,45-$ $65,66-85$ and $>85 \mathrm{nmol} / \mathrm{l}$ ) and the clinical definition of vitamin D deficiency (above and below a blood serum 25(OH)D concentration of $30 \mathrm{nmol} / 1)^{(21)}$. The likelihood ratio test (LRT) was used to evaluate the statistical significance of continuous plasma $25(\mathrm{OH}) \mathrm{D}$ and $25(\mathrm{OH}) \mathrm{D}$ quartiles. Owing to the small number of observations in some cells, exact methods were used for estimating CI and $P$ values for the relationships of long LTL and vitamin $\mathrm{D}$ deficiency.

The following factors were considered as potential confounders because they could be associated with both LTL and plasma 25(OH)D concentrations, but were not believed to be on the causal pathway: age, sex, race, BMI, smoking history, indoor physical activity, season of blood collection, cumulative occupational radiation dose to the red bone marrow, menopausal status and use of menopausal hormone therapy. We also examined vitamin D supplementation because, although it may contribute to plasma $25(\mathrm{OH}) \mathrm{D}$ concentrations, it may serve as a surrogate for other general health-related behaviours that may impact LTL as well. These factors were first examined in relation to long LTL using log-LRT and plasma 25(OH)D using $F$-tests from linear regression models; the square root transformation of $25(\mathrm{OH}) \mathrm{D}$ suggested normally distributed residuals.

Final regression models included age at blood sample collection, sex, race and season of blood sample collection for a priori reasons because they were considered in previous 
publications or were strong risk factors for LTL in this cohort. Forward selection was used to assess the impact of additional potential confounders on model fit using log-LRT; however, none of them provided an improvement in fit. Non-linearity of the relationship between plasma $25(\mathrm{OH}) \mathrm{D}$ and long LTL was assessed in regression models by including a plasma $25(\mathrm{OH}) \mathrm{D}$ squared term. Differences in the relationship between plasma 25 $(\mathrm{OH}) \mathrm{D}$ and long LTL across the entire range of plasma $25(\mathrm{OH}) \mathrm{D}$ were assessed by testing for heterogeneity across plasma $25(\mathrm{OH})$ $\mathrm{D}$ quartiles. Effect modification of the relationship between continuous plasma $25(\mathrm{OH}) \mathrm{D}$, vitamin D deficiency and long LTL was assessed across race, sex and race-sex subgroups. Missing values were coded as separate categories and were included as indicator variables in the models unless otherwise noted.

Statistical tests were two-sided, and $p$ values were considered significant at the $0.05 \alpha$ level. Analyses were performed using SAS version 9.3 (SAS Institute Inc.). For certain analyses involving small numbers of events (Table 4), exact logistic regression analyses were conducted using LogXact-11 version 11.0.0 (Cytel Inc., 1989-2015).

\section{Results}

The study population included 1154 participants with a mean age at blood sample collection of 63.2 years (data not shown). The odds of long LTL were higher for participants of younger age, black race, BMI of $35 \mathrm{~kg} / \mathrm{m}^{2}$ or higher and blood sample collection during the summer (Table 1). They were also higher for females, but the relationship was of borderline statistical significance. Smoking history, indoor physical activity, cumulative estimated ionising radiation dose to the red bone marrow, menopausal status and use of menopausal hormone therapy were not associated with odds of long LTL. Plasma 25(OH)D concentrations were significantly higher in participants of older age, whites ( $v$. blacks), those reporting longer time being physically active, participants who reported using vitamin D supplements and menopausal hormone therapy users (Table 2).

We found no significant relationship between continuous 25 $(\mathrm{OH}) \mathrm{D}$ concentration and long LTL in the total population $\left(P_{\text {trend }}=0.440\right)$, nor in white females $\left(P_{\text {trend }}=0.845\right)$, white males $\left(P_{\text {trend }}=0.636\right)$, black females $\left(P_{\text {trend }}=0.967\right)$ or black males $\left(P_{\text {trend }}=0.484\right)$, after adjusting for age at blood sample collection (years), race, sex and season (Table 3). We found no significant associations for quartiles of plasma $25(\mathrm{OH}) \mathrm{D}$ concentration and long LTL in the total population or among subgroups of race and sex for most quartiles of plasma 25(OH)D after adjusting for age at blood sample collection (years), race, sex and season (Table 3). The exception was a significantly increased odds of long LTL among men with plasma 25(OH)D of quartile $2 v$. quartile 1 (OR 1.90; $95 \%$ CI 1.10, 3.32). A test of heterogeneity for long LTL among males did not indicate a significant difference across plasma 25(OH)D quartiles ( $\left.P_{\text {heterogeneity }}=0.084\right)$; however, tests of non-linearity with the inclusion of a plasma $25(\mathrm{OH}) \mathrm{D}$ squared term in the final models did indicate significant non-linearity among all males (LRT $P$ value $=0 \cdot 020)$ and among black males (LRT $P$ value $=0.049)$. Multiplicative interaction tests of continuous 25(OH)D and long LTL were NS for sex, race or race-sex categories (Table 3).
Similarly, we found no significant relationship between vitamin D deficiency (based on the Institute of Medicine's cut-off value of $30 \mathrm{nmol} / 1$ for plasma $25(\mathrm{OH}) \mathrm{D}$ concentration) in relation to long LTL in the total population and in most race and sex subgroups (Table 4). An exception was among whites, for whom we found that vitamin D non-deficiency $(\geq 30 \mathrm{nmol} / \mathrm{l})$ was associated with significantly increased odds of long LTL (OR 2.67; 95\% CI 1.16, 6.61; $P$ value $=0.024$ ), after adjustment for age (5-year categories), race and season. In addition, we also found a significantly increased odds of long LTL associated with vitamin $\mathrm{D}$ non-deficiency among white males $(P$ value $=$ 0.005). We found no significant interaction on the multiplicative scale between vitamin D deficiency and long LTL for race, sex or race-sex subgroups (Table 4).

\section{Discussion}

To our knowledge, this is the first study to examine the vitamin D and telomere length associations across sex and race subgroups. We found no significant associations between continuous 25(OH)Dconcentration and long LTL for our overall analysis population or in whites, blacks, females, males or racesex subgroups. However, we found that non-deficient concentrations of vitamin D ( $\geq 30 \mathrm{nmol} / \mathrm{l})$ were significantly associated with longer LTL in whites.

We also examined how sex and race were associated with telomere length after adjusting for age. Our finding that women had borderline significantly higher odds of long LTL than men was consistent with a recent meta-analysis of thirty-six cohorts $^{(22)}$. We also found a significant age-adjusted association between white $v$. black race and long LTL, with blacks having higher odds for long LTL. Previous studies of adults reported whites having either significantly longer ${ }^{(23)}$ or shorter $^{(24)}$ telomeres than blacks.

Although we did not find significant linear associations between 25(OH)D and long LTL, we found that vitamin D nondeficiency $(25(\mathrm{OH}) \mathrm{D}$ concentration $\geq 30 \mathrm{nmol} / \mathrm{l})$ was significantly associated with increased odds of long LTL in whites. These findings should be cautiously interpreted given the small number of vitamin D-deficient participants. Moreover, as we did not identify a statistically significant interaction by race, our data do not support racial differences in the vitamin D-telomere length relationship.

In contrast to the significantly positive linear association between $25(\mathrm{OH}) \mathrm{D}$ concentration and telomere length that was found in two previous studies of white women ${ }^{(1,2)}$, we did not find a significant association among the white women in our study population. Compared with these studies, we had a smaller number of white women ( $n$ 373), and therefore lower statistical power for examining associations within this subgroup. Age differences may have contributed to the different findings, because the age range for white women in our population was 48-93 years (mean age $=62 \cdot 8$ ), whereas Richards et $a l .{ }^{(1)}$ studied younger women aged $18-79$ years (mean age $=49.4$ years) and Liu et al ${ }^{(2)}$ studied women under 69 years of age (mean age $=59 \cdot 4$ ). However, we note that Williams et al. ${ }^{(13)}$ found no relationship in predominantly white women who were young adults. Given the 
Table 1. Distribution of leucocyte telomere length (LTL) quartiles $(Q)$ of long $v$. short LTL in relation to demographic and other characteristics of 1154 US radiologic technologists, 2008-2009

(Numbers and percentages; odds ratios and $95 \%$ confidence intervals)

\begin{tabular}{|c|c|c|c|c|c|c|c|c|c|c|c|c|}
\hline \multirow[b]{3}{*}{ Characteristics } & \multirow[b]{3}{*}{ No. } & \multicolumn{8}{|c|}{ LTL quartile* } & & & \\
\hline & & \multicolumn{2}{|c|}{ Q1 (lowest) } & \multicolumn{2}{|c|}{ Q2 } & \multicolumn{2}{|c|}{ Q3 } & \multicolumn{2}{|c|}{ Q4 (highest) } & \multicolumn{2}{|c|}{ Long LTL† } & \multirow[b]{2}{*}{$P(\mathrm{df}) \ddagger$} \\
\hline & & $n$ & $\%$ & $n$ & $\%$ & $n$ & $\%$ & $n$ & $\%$ & OR & $95 \% \mathrm{Cl}$ & \\
\hline Total & 1154 & \multicolumn{2}{|c|}{288} & \multicolumn{2}{|c|}{289} & \multicolumn{2}{|c|}{288} & \multicolumn{2}{|c|}{289} & & & \\
\hline \multicolumn{13}{|l|}{ Age at blood sample collection (years) } \\
\hline $48-64$ & 678 & 126 & 44 & 153 & 53 & 185 & 64 & 214 & 74 & & Ref. & \\
\hline $65-93$ & 476 & 162 & 56 & 136 & 47 & 103 & 36 & 75 & 26 & 0.42 & $0.33,0.53$ & $<0.001(1)$ \\
\hline \multicolumn{13}{|l|}{ Race } \\
\hline Whites & 651 & 163 & 57 & 184 & 64 & 162 & 56 & 142 & 49 & & Ref. & \\
\hline Blacks & 503 & 125 & 43 & 105 & 36 & 126 & 44 & 147 & 51 & 1.33 & $1.04,1.69$ & $0.021(1)$ \\
\hline Sex & & & & & & & & & & & & \\
\hline Females & 711 & 157 & 55 & 175 & 61 & 180 & 63 & 199 & 69 & & Ref. & \\
\hline Males & 443 & 131 & 45 & 114 & 39 & 108 & 38 & 90 & 31 & 0.79 & $0 \cdot 62,1 \cdot 01$ & 0.060 (1) \\
\hline Race and sex & & & & & & & & & & & & \\
\hline White females & 373 & 82 & 28 & 103 & 36 & 91 & 32 & 97 & 34 & & Ref. & \\
\hline White males & 278 & 81 & 28 & 81 & 28 & 71 & 25 & 45 & 16 & 0.75 & $0.54,1.04$ & \\
\hline Black females & 338 & 75 & 26 & 72 & 25 & 89 & 31 & 102 & 35 & 1.22 & $0.90,1.65$ & \\
\hline Black males & 165 & 50 & 17 & 33 & 11 & 37 & 13 & 45 & 16 & $1 \cdot 10$ & $0.75,1.61$ & $0.035(3)$ \\
\hline Smoking status & & & & & & & & & & & & \\
\hline Never & 565 & 135 & 47 & 134 & 46 & 141 & 49 & 155 & 54 & & Ref. & \\
\hline Former & 459 & 116 & 40 & 126 & 44 & 115 & 40 & 102 & 35 & 0.96 & $0.74,1.24$ & \\
\hline Current & 105 & 30 & 10 & 25 & 9 & 26 & 9 & 24 & 8 & 0.71 & $0.46,1 \cdot 10$ & \\
\hline Unknown & 25 & 7 & 2 & 4 & 1 & 6 & 2 & 8 & 3 & 1.27 & $0.56,2.98$ & $0.412(3)$ \\
\hline BMI $\left(\mathrm{kg} / \mathrm{m}^{2}\right)$ & & & & & & & & & & & & \\
\hline$<25$ & 283 & 85 & 30 & 70 & 24 & 66 & 23 & 62 & 21 & & Ref. & \\
\hline $25-29$ & 473 & 112 & 39 & 126 & 44 & 123 & 43 & 112 & 39 & 1.20 & $0.89,1.63$ & \\
\hline $30-34$ & 222 & 59 & 20 & 51 & 18 & 57 & 20 & 55 & 19 & 1.22 & $0.85,1.75$ & \\
\hline $35+$ & 165 & 29 & 10 & 41 & 14 & 40 & 14 & 55 & 19 & 1.50 & $1.00,2 \cdot 23$ & \\
\hline Unknown & 11 & 3 & 1 & 1 & 0 & 2 & 1 & 5 & 2 & $2 \cdot 61$ & $0.73,10.6$ & $0.059(1)$ \\
\hline $\begin{array}{l}\text { Time spent being physically active ind } \\
\text { last } 30 \mathrm{~d}\end{array}$ & & & & & & & & & & & & \\
\hline$<1 \mathrm{~h} /$ week & 335 & 92 & 32 & 78 & 27 & 92 & 32 & 73 & 25 & & Ref. & \\
\hline $1-2 \mathrm{~h} /$ week & 293 & 61 & 21 & 80 & 28 & 63 & 22 & 89 & 31 & 1.01 & $0.73,1.40$ & \\
\hline $3+h /$ week & 444 & 107 & 37 & 112 & 39 & 118 & 41 & 107 & 37 & 0.97 & $0.72,1.30$ & \\
\hline Unknown & 82 & 28 & 10 & 19 & 7 & 15 & 5 & 20 & 7 & 1.06 & $0.63,1.76$ & $0.879(1)$ \\
\hline Took vitamin D supplements in the last & & & & & & & & & & & & \\
\hline Never & 610 & 152 & 53 & 149 & 52 & 148 & 51 & 161 & 56 & & Ref. & \\
\hline Ever & 466 & 111 & 39 & 125 & 43 & 122 & 42 & 108 & 37 & 1.11 & $0.86,1.42$ & \\
\hline Unknown & 78 & 25 & 9 & 15 & 5 & 18 & 6 & 20 & 7 & $1 \cdot 13$ & $0.69,1.85$ & $0.701(2)$ \\
\hline Season of blood collection & & & & & & & & & & & & \\
\hline Winter & 398 & 103 & 36 & 110 & 38 & 90 & 31 & 95 & 33 & & Ref. & \\
\hline Spring & 331 & 78 & 27 & 94 & 33 & 90 & 31 & 69 & 24 & 1.17 & $0.86,1.58$ & \\
\hline Summer & 178 & 45 & 16 & 32 & 11 & 51 & 18 & 50 & 17 & 1.69 & $1.17,2.46$ & \\
\hline Fall & 247 & 62 & 22 & 53 & 18 & 57 & 20 & 75 & 26 & 1.34 & $0.94,1.86$ & $0.034(3)$ \\
\hline $\begin{array}{l}\text { Occupational radiation dose to the red } \\
\text { (mGy) }\end{array}$ & & & & & & & & & & & & \\
\hline $0-9$ & 873 & 194 & 67 & 207 & 72 & 233 & 81 & 239 & 83 & & Ref. & \\
\hline $10-19$ & 219 & 76 & 26 & 63 & 22 & 40 & 14 & 40 & 14 & 0.81 & $0.57,1.13$ & \\
\hline 20-135 & 62 & 18 & 6 & 19 & 7 & 15 & 5 & 10 & 3 & 1.25 & $0.70,2.20$ & $0.366(1)$ \\
\hline Menopausal status & & & & & & & & & & & & \\
\hline Premenopausal or perimenopausal & 28 & 6 & 4 & 4 & 2 & 6 & 3 & 12 & 6 & & Ref. & \\
\hline Postmenopausal & 635 & 139 & 89 & 164 & 94 & 161 & 89 & 171 & 86 & 1.15 & $0.49,2.57$ & \\
\hline Unknown & 48 & 12 & 8 & 7 & 4 & 13 & 7 & 16 & 8 & 1.39 & $0.50,3.72$ & $0.783(2)$ \\
\hline Menopausal hormone therapy use, am & & & & & & & & & & & & \\
\hline Never & 311 & 66 & 42 & 73 & 42 & 77 & 43 & 95 & 48 & & Ref. & \\
\hline Former & 267 & 63 & 40 & 68 & 39 & 69 & 38 & 67 & 34 & 1.01 & $0.72,1.42$ & \\
\hline Current & 97 & 21 & 13 & 26 & 15 & 24 & 13 & 26 & 13 & 0.82 & $0.51,1.31$ & \\
\hline Unknown & 36 & 7 & 4 & 8 & 5 & 10 & 6 & 11 & 6 & 1.28 & $0.63,2.66$ & 0.710 (3) \\
\hline
\end{tabular}

Ref., referent values; mGy, milligrey.

* Normalised LTL quartiles: Q1 is 0.1113319 to $<0.2988862$, Q2 is 0.2988862 to $<0.3395012$, Q3 is 0.3395012 to $<0.3909937$ and Q4 is 0.3909937 to $<1.0467953$.

† OR based on logistic regression of long (above median 0.3395012) v. short normalised LTL with all models adjusted for continuous age at blood sample collection except for age at sample collection.

$\ddagger P$ values based on likelihood ratio test from logistic regression of long $v$. short LTL using categorical variables as presented in the table except for age at blood sample collection (years), occupational radiation dose (mGy), continuous BMI (coded 1 through 4) and continuous physical activity (coded 1 through 3 ) with corresponding missing observations dropped from these analyses. All models adjusted for continuous age at blood sample collection except for age at blood sample collection. 
Table 2. Distribution of plasma 25-hydroxyvitamin $\mathrm{D}(25(\mathrm{OH}) \mathrm{D})$ quartiles $(\mathrm{Q})$ in relation to demographic and other characteristics of $1154 \mathrm{US}$ radiologic technologists, 2008-2009

(Numbers and percentages)

\begin{tabular}{|c|c|c|c|c|c|c|c|c|c|c|}
\hline \multirow[b]{3}{*}{ Characteristics } & \multicolumn{8}{|c|}{ Plasma 25(OH)D quartile } & \multirow{3}{*}{$\begin{array}{l}\text { Plasma 25(OH)D } \\
\text { (median, } \mathrm{nmol} / \mathrm{l} \text { ) }\end{array}$} & \multirow[b]{3}{*}{$P(\mathrm{df})^{\star} \dagger$} \\
\hline & \multicolumn{2}{|c|}{$\begin{array}{c}\mathrm{Q} 1 \\
(<45 \mathrm{nmol} / \mathrm{l})\end{array}$} & \multicolumn{2}{|c|}{$\begin{array}{c}\mathrm{Q} 2 \\
(45-65 \mathrm{nmol} / \mathrm{l}) \\
\end{array}$} & \multicolumn{2}{|c|}{$\begin{array}{c}\mathrm{Q} 3 \\
(66-85 \mathrm{nmol} / \mathrm{l}) \\
\end{array}$} & \multicolumn{2}{|c|}{$\begin{array}{c}\text { Q4 } \\
(>85 \mathrm{nmol} / \mathrm{l}) \\
\end{array}$} & & \\
\hline & $n$ & $\%$ & $n$ & $\%$ & $n$ & $\%$ & $n$ & $\%$ & & \\
\hline Total & \multicolumn{2}{|c|}{287} & \multicolumn{2}{|c|}{290} & \multicolumn{2}{|c|}{289} & \multicolumn{2}{|c|}{288} & & \\
\hline Age at blood sample collection (years) & & & & & & & & & & \\
\hline $48-64$ & 196 & 68 & 180 & 62 & 168 & 58 & 134 & 47 & $62 \cdot 1$ & \\
\hline $65-93$ & 91 & 32 & 110 & 38 & 121 & 42 & 154 & 53 & $70 \cdot 7$ & $<0.001(1)$ \\
\hline \multicolumn{11}{|l|}{ Race } \\
\hline Whites & 106 & 37 & 163 & 56 & 191 & 66 & 191 & 66 & $71 \cdot 3$ & \\
\hline Blacks & 181 & 63 & 127 & 44 & 98 & 34 & 97 & 34 & $57 \cdot 6$ & $<0.001$ \\
\hline \multicolumn{11}{|l|}{ Sex } \\
\hline Females & 190 & 66 & 148 & 51 & 187 & 65 & 186 & 65 & $67 \cdot 8$ & \\
\hline Males & 97 & 34 & 142 & 49 & 102 & 35 & 102 & 35 & $64 \cdot 1$ & $0.615(1)$ \\
\hline \multicolumn{11}{|l|}{ Race and sex } \\
\hline White females & 62 & 22 & 77 & 27 & 119 & 41 & 115 & 40 & 73.4 & \\
\hline White males & 44 & 15 & 86 & 30 & 72 & 25 & 76 & 26 & 68.2 & \\
\hline Black females & 128 & 45 & 71 & 24 & 68 & 24 & 71 & 25 & $57 \cdot 0$ & \\
\hline Black males & 53 & 18 & 56 & 19 & 30 & 10 & 26 & 9 & $58 \cdot 6$ & $<0.001$ \\
\hline \multicolumn{11}{|l|}{ Smoking status } \\
\hline Never & 141 & 49 & 138 & 48 & 138 & 48 & 148 & 51 & $66 \cdot 5$ & \\
\hline Former & 99 & 34 & 127 & 44 & 118 & 41 & 115 & 40 & $66 \cdot 4$ & \\
\hline Current & 39 & 14 & 18 & 6 & 25 & 9 & 23 & 8 & $62 \cdot 9$ & \\
\hline Unknown & 8 & 3 & 7 & 2 & 8 & 3 & 2 & 1 & $59 \cdot 2$ & 0.199 (3) \\
\hline $\mathrm{BMI}\left(\mathrm{kg} / \mathrm{m}^{2}\right)$ & & & & & & & & & & \\
\hline$<25$ & 47 & 16 & 62 & 21 & 71 & 25 & 103 & 36 & $75 \cdot 7$ & \\
\hline $25-29$ & 100 & 35 & 120 & 41 & 140 & 48 & 113 & 39 & 68.0 & \\
\hline $30-34$ & 67 & 23 & 65 & 22 & 47 & 16 & 43 & 15 & $59 \cdot 1$ & \\
\hline $35+$ & 69 & 24 & 40 & 14 & 30 & 10 & 26 & 9 & 53.3 & \\
\hline Unknown & 4 & 1 & 3 & 1 & 1 & 0 & 3 & 1 & $56 \cdot 0$ & $<0.001(1)$ \\
\hline $\begin{array}{l}\text { Time spent being physically active indo } \\
\text { during the last } 30 \mathrm{~d}\end{array}$ & & & & & & & & & & \\
\hline$<1 \mathrm{~h} /$ week & 95 & 33 & 92 & 32 & 80 & 28 & 68 & 24 & 61.4 & \\
\hline $1-2 \mathrm{~h} /$ week & 70 & 24 & 79 & 27 & 67 & 23 & 77 & 27 & $66 \cdot 0$ & \\
\hline $3+h /$ week & 101 & 35 & 104 & 36 & 119 & 41 & 120 & 42 & $68 \cdot 4$ & \\
\hline Unknown & 21 & 7 & 15 & 5 & 23 & 8 & 23 & 8 & 69.5 & $0.020(1)$ \\
\hline Took vitamin D supplements in the last & & & & & & & & & & \\
\hline Never & 217 & 76 & 187 & 64 & 120 & 42 & 86 & 30 & $54 \cdot 1$ & \\
\hline Ever & 51 & 18 & 83 & 29 & 147 & 51 & 185 & 64 & 78.0 & \\
\hline Unknown & 19 & 7 & 20 & 7 & 22 & 8 & 17 & 6 & 65.5 & $<0.001(2)$ \\
\hline Season of blood sample collection & & & & & & & & & & \\
\hline Winter & 116 & 40 & 100 & 34 & 88 & 30 & 94 & 33 & $62 \cdot 6$ & \\
\hline Spring & 78 & 27 & 86 & 30 & 89 & 31 & 78 & 27 & $66 \cdot 3$ & \\
\hline Summer & 39 & 14 & 44 & 15 & 46 & 16 & 49 & 17 & $68 \cdot 1$ & \\
\hline Fall & 54 & 19 & 60 & 21 & 66 & 23 & 67 & 23 & $69 \cdot 3$ & $0.123(3)$ \\
\hline $\begin{array}{l}\text { Occupational radiation dose to the red } \\
\text { marrow(mGy) }\end{array}$ & & & & & & & & & & \\
\hline $0-9$ & 226 & 79 & 217 & 75 & 226 & 78 & 204 & 71 & $65 \cdot 6$ & \\
\hline $10-19$ & 45 & 16 & 57 & 20 & 55 & 19 & 62 & 22 & 68.4 & \\
\hline $20-135$ & 16 & 6 & 16 & 6 & 8 & 3 & 22 & 8 & 64.5 & $0.890(1)$ \\
\hline Menopausal status, among females & & & & & & & & & & \\
\hline Premenopausal or perimenopausal & 10 & 5 & 8 & 5 & 8 & 4 & 2 & 1 & $57 \cdot 0$ & \\
\hline Postmenopausal & 164 & 86 & 131 & 89 & 166 & 89 & 174 & 94 & 68.3 & \\
\hline Unknown & 16 & 8 & 9 & 6 & 13 & 7 & 10 & 5 & 63.5 & $0.430(2)$ \\
\hline $\begin{array}{l}\text { Menopausal hormone therapy use, am } \\
\text { females }\end{array}$ & & & & & & & & & & \\
\hline Never & 104 & 55 & 67 & 45 & 74 & 40 & 66 & 35 & $61 \cdot 8$ & \\
\hline Former & 53 & 28 & 58 & 39 & 72 & 39 & 84 & 45 & 71.4 & \\
\hline Current & 21 & 11 & 13 & 9 & 35 & 19 & 28 & 15 & $72 \cdot 5$ & \\
\hline Unknown & 12 & 6 & 10 & 7 & 6 & 3 & 8 & 4 & $55 \cdot 3$ & $<0.001(3)$ \\
\hline
\end{tabular}

mGy, milligrey.

* $P$ values based on $F$-test from linear regression of square root of plasma 25(OH)D as the outcome with independent factors coded categorically as shown in table, except for continuous age at blood sample collection (years), continuous BMI (coded 1 through 4), continuous physical activity (coded 1 through 3 ) and occupational radiation dose (mGy). $\dagger$ All $P$ values adjusted for continuous age at blood sample collection except for age at blood sample collection. Observations with unknowns for continuous variables removed from

the analyses. 
Table 3. Long (above median) v. short leucocyte telomere length (LTL) in relation to plasma 25-hydroxyvitamin $D(25(O H) D)$ quartile (Q) in 1154 US radiologic technologists by race and sex

(Odds ratios and $95 \%$ confidence intervals)

\begin{tabular}{|c|c|c|c|c|c|c|c|c|c|c|c|c|}
\hline & \multirow[b]{3}{*}{ No. } & \multicolumn{8}{|c|}{ Odds ratios* of long LTL and $95 \% \mathrm{Cl}$ by plasma $25(\mathrm{OH}) \mathrm{D}$ quartile $†$} & \multirow[b]{3}{*}{$P_{\text {for trend }} \ddagger$} & \multirow[b]{3}{*}{$P_{\text {for heterogeneity } \S}$} & \multirow[b]{3}{*}{$P_{\text {for interaction }}(\mathrm{df}) \|$} \\
\hline & & \multicolumn{2}{|c|}{ Q1 $(<45 \mathrm{nmol} / \mathrm{l})$} & \multicolumn{2}{|c|}{ Q2 $(45-65 \mathrm{nmol} / \mathrm{l})$} & \multicolumn{2}{|c|}{ Q3 $(66-85 \mathrm{nmol} / \mathrm{l})$} & \multicolumn{2}{|c|}{ Q4 (>85 nmol/l) } & & & \\
\hline & & OR & $95 \% \mathrm{Cl}$ & OR & $95 \% \mathrm{Cl}$ & OR & $95 \% \mathrm{Cl}$ & OR & $95 \% \mathrm{Cl}$ & & & \\
\hline Total & 1154 & & Ref. & 1.22 & $0.86,1.72$ & $1 \cdot 13$ & $0.80,1.61$ & 0.98 & $0.69,1.40$ & 0.440 & 0.552 & \\
\hline \multicolumn{13}{|l|}{ Race } \\
\hline White & 651 & & Ref. & 1.44 & $0.86,2 \cdot 41$ & $1 \cdot 25$ & $0.76,2.06$ & 1.05 & $0.63,1.73$ & 0.643 & 0.410 & \multirow[t]{2}{*}{$P_{\text {race }}=0.872(3)$} \\
\hline Black & 503 & & Ref. & 1.05 & $0.65,1.70$ & 1.08 & $0.64,1.81$ & 0.99 & $0.59,1.68$ & 0.555 & 0.990 & \\
\hline \multicolumn{13}{|c|}{ 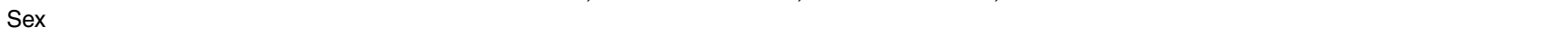 } \\
\hline Females & 711 & & Ref. & 0.87 & $0.56,1.37$ & 1.04 & $0.68,1.61$ & 0.92 & $0.60,1.43$ & 0.789 & 0.861 & \multirow[t]{2}{*}{$P_{\mathrm{sex}}=0.159(3)$} \\
\hline Males & 443 & & Ref. & 1.90 & $1 \cdot 10,3 \cdot 32$ & $1 \cdot 31$ & $0.72,2 \cdot 41$ & $1 \cdot 11$ & $0.59,2.07$ & 0.348 & 0.084 & \\
\hline \multicolumn{13}{|l|}{ Race and sex } \\
\hline White females & 373 & & Ref. & $1 \cdot 12$ & $0.56,2.24$ & 1.29 & $0.68,2.47$ & 1.02 & $0.53,1.94$ & 0.845 & 0.798 & \multirow[t]{4}{*}{$P_{\text {race,sex }}=0.654(9)$} \\
\hline White males & 278 & & Ref. & 1.87 & $0.87,4.12$ & $1 \cdot 17$ & $0.53,2.66$ & $1 \cdot 10$ & $0.49,2.50$ & 0.636 & 0.265 & \\
\hline Black females & 338 & & Ref. & 0.74 & $0.40,1.35$ & 0.90 & $0.48,1.68$ & 0.98 & $0.52,1.83$ & 0.967 & 0.783 & \\
\hline Black males & 165 & & Ref. & 1.96 & $0.88,4.48$ & $1 \cdot 76$ & $0.66,4.84$ & $1 \cdot 18$ & $0.40,3.43$ & 0.484 & 0.359 & \\
\hline
\end{tabular}

Ref., referent values.

* Adjusted for age at blood sample collection (continuous), season (categorical), race (in total population and sex-specific results) and sex (total population and race-specific results).

† Plasma 25(OH)D cut-off values based on total study population.

$\mp$ Trend $P$ values from likelihood ratio test calculated using continuous plasma $25(\mathrm{OH}) \mathrm{D}, \mathrm{df}=1$

$\S$ Heterogeneity $P$ values from likelihood ratio test of differences in OR between four quartiles, $\mathrm{df}=3$.

$\|$ Multiplicative interaction $P$ values from likelihood ratio test using continuous plasma $25(\mathrm{OH}) \mathrm{D}$.

Table 4. Long $v$. short leucocyte telomere length (LTL) for plasma 25 -hydroxyvitamin $\mathrm{D}(25(\mathrm{OH}) \mathrm{D}) \geq 30 \mathrm{v}$. $<30 \mathrm{nmol} / \mathrm{l}$ in $1154 \mathrm{US}$ radiologic technologists by race and sex

(Odds ratios and $95 \%$ confidence intervals)

\begin{tabular}{|c|c|c|c|c|c|c|}
\hline & \multicolumn{2}{|c|}{ No. long LTL/no. short LTL* } & \multicolumn{2}{|c|}{ Long LTL† } & \multirow[b]{2}{*}{$P \dagger$} & \multirow[b]{2}{*}{$P_{\text {for interaction }}(\mathrm{df}) \ddagger$} \\
\hline & $\geq 30 \mathrm{nmol} / \mathrm{l}$ & $<30 \mathrm{nmol} / \mathrm{l}$ & OR & $95 \% \mathrm{Cl}$ & & \\
\hline Total & $518 / 519$ & $59 / 58$ & 1.38 & $0.89,2.14$ & 0.161 & \\
\hline \multicolumn{7}{|l|}{ Race } \\
\hline Whites & $295 / 323$ & $9 / 24$ & $2 \cdot 67$ & $1 \cdot 16,6 \cdot 61$ & 0.024 & \multirow[t]{2}{*}{$P_{\text {race }}=0.083(1)$} \\
\hline Blacks & $223 / 196$ & $50 / 34$ & 1.04 & $0.61,1.77$ & 0.931 & \\
\hline \multicolumn{7}{|l|}{ Sex } \\
\hline Females & $331 / 294$ & $48 / 38$ & 1.23 & $0.74,2.04$ & 0.466 & \multirow[t]{2}{*}{$P_{\text {sex }}=0.463(1)$} \\
\hline Males & $187 / 225$ & $11 / 20$ & 1.94 & $0.81,4.97$ & 0.168 & \\
\hline \multicolumn{7}{|l|}{ Race and sex } \\
\hline White females & $179 / 173$ & $9 / 12$ & 1.50 & $0.57,4.10$ & 0.489 & \multirow{4}{*}{$P_{\text {race,sex }}=0.261(3)$} \\
\hline White males & $116 / 150$ & $0 / 12$ & INF & $2 \cdot 28$, INF & 0.005 & \\
\hline Black females & $152 / 121$ & $39 / 26$ & $1 \cdot 14$ & $0.62,2.07$ & 0.732 & \\
\hline Black males & $71 / 75$ & $11 / 8$ & 0.78 & $0.25,2.41$ & 0.765 & \\
\hline
\end{tabular}

INF, positive infinity.

* Categorisation of long and short LTL on the basis of median normalised LTL in total population.

† OR based on maximum likelihood estimate from logistic regression with exact mid- $P$ Cl; adjusted by stratification for 5-year age categories (48-49, 50-54, 54-59, 60-64, 65-69, 70-74, 75-79, 80-84, 85-89, 90-93 years), season (categorical), race (white, black) and sex.

$\ddagger P$ values for multiplicative interaction use exact score tests, with adjustment by stratification as described above.

limited number of studies on the vitamin D-telomere length relationship in women, it remains unclear whether there is a relationship between these two factors. With regard to men, our null findings were consistent with those of Julin et al. ${ }^{(4)}$ as well as those of Williams et al. ${ }^{(13)}$.

Although our results were null, the rationale for studying the relationship between vitamin D and LTL remains plausible, given the potential anti-inflammatory role of vitamin $\mathrm{D}$ and the sensitivity of telomeres to inflammation. Vitamin D has been inversely related to several inflammatory diseases such as rheumatoid arthritis, systemic lupus erythematosus and multiple sclerosis ${ }^{(25)}$. In experimental studies, vitamin $\mathrm{D}$ metabolites inhibited production by human monocytes of inflammatory cytokines including IL-6 and TNF- $\alpha^{(26)}$. In cross-sectional study populations, the predominant circulating metabolite $(25(\mathrm{OH}) \mathrm{D})$ was inversely linked to the inflammatory marker $\mathrm{C}$-reactive protein in persons with low $25(\mathrm{OH}) \mathrm{D}$ levels and those with elevated inflammatory states ${ }^{(8)}$. Likewise, shortened LTL has been observed in groups with medical conditions related to inflammation such as vascular disease and arthritis ${ }^{(27,28)}$, and has been related to behaviours/conditions that are themselves associated with inflammation, such as cigarette smoking and obesity ${ }^{(29)}$.

Our findings should be interpreted in the context of several limitations. Despite having a reasonably large overall sample size, this analysis still had limited statistical power for formal tests of effect modification by sex and race. Similar to previous studies 
of this association $^{(1-3)}$, the analysis was cross-sectional and could not establish temporality. As we only measured 25(OH)D concentration at a single timepoint, those concentrations may not reflect the average long-term vitamin $\mathrm{D}$ status, which may be more relevant to vitamin D's potential effects on telomere length.

Overall, our study aimed to expand the generalisability of the vitamin $\mathrm{D}$ and telomere length associations previously reported, because most assessments have been limited to white females. Larger studies will be needed to better test for effect modification by sex or race for associations involving vitamin D. Finally, longitudinal studies examining multiple measurements of 25(OH)D and LTL in individual participants can help establish temporality, control for person-level differences and examine associations involving changes in telomere length.

\section{Acknowledgements}

The authors thank the radiologic technologists who participated in the USRT study; Bruce Alexander, Diane Kampa and Allison Iwan of the University of Minnesota for study management, survey administration and blood specimen collection; Roy Van Dusen of Information Management Services, Inc. for data management; Wayne Liu for computing support; and Cancer Genomics Research Laboratory for study management, sample handling and telomere assay performance analysis. The authors also thank Dr Ron Horst of Heartland Assays Inc., for performing 25-hydroxvitamin D assays on the plasma samples.

This work was supported by the Intramural Research Program of the Division of Cancer Epidemiology and Genetics, National Cancer Institute, National Institutes of Health.

Designed the study: J. J. L., M. S. L., M. P. L., S. A. S., D. M. F.; performed data collection: C. L. D., H. H.; performed statistical analyses: E. K. C., M. P. L.; drafted the article: J. J. L., E. K. C., D. M. F.; critically reviewed the article: all authors.

There are no conflicts of interest.

\section{References}

1. Richards JB, Valdes AM, Gardner JP, et al. (2007) Higher serum vitamin $\mathrm{D}$ concentrations are associated with longer leukocyte telomere length in women. Am J ClinNutr 86, $1420-1425$.

2. Liu JJ, Prescott J, Giovannucci E, et al. (2013) Plasma vitamin D biomarkers and leukocyte telomere length. Am J Epidemiol 177, 1411-1417.

3. Hoffecker BM, Raffield LM, Kamen DL, et al. (2013) Systemic lupus erythematosus and vitamin D deficiency are associated with shorter telomere length among African Americans: a case-control study. PLOS ONE 8, e63725.

4. Julin B, Shui IM, Prescott J, et al. (2015) Plasma vitamin D biomarkers and leukocyte telomere length in men. Eur J Nutr (epublication ahead of print version 11 November 2015).

5. Holick MF (2007) Vitamin D deficiency. $N$ Engl J Med 357, 266-281.

6. Reichel H, Koeffler HP \& Norman AW (1989) The role of the vitamin $\mathrm{D}$ endocrine system in health and disease. $N$ Engl J Med 320, 980-991.

7. Deeb KK, Trump DL \& Johnson CS (2007) Vitamin D signalling pathways in cancer: potential for anticancer therapeutics. Nat Rev Cancer 7, 684-700.
8. Zanetti M, Harris SS \& Dawson-Hughes B (2014) Ability of vitamin $\mathrm{D}$ to reduce inflammation in adults without acute illness. Nutr Rev 72, 95-98.

9. Blackburn EH (1991) Structure and function of telomeres. Nature 350, 569-573.

10. Houben JM, Moonen HJ, van Schooten FJ, et al. (2008) Telomere length assessment: biomarker of chronic oxidative stress? Free RadicBiol Med 44, 235-246.

11. Pooley KA, Sandhu MS, Tyrer J, et al. (2010) Telomere length in prospective and retrospective cancer case-control studies. Cancer Res 70, 3170-3176.

12. Bojesen SE (2013) Telomeres and human health. J Intern Med 274, 399-413.

13. Williams DM, Palaniswamy S, Sebert S, et al. (2016) 25-Hydroxyvitamin D concentration and leukocyte telomere length in young adults: findings from the Northern Finland birth cohort 1966. Am J Epidemiol 183, 191-198.

14. Boice JD Jr, Mandel JS, Doody MM, et al. (1992) A health survey of radiologic technologists. Cancer 69, 586-598.

15. Doody MM, Mandel JS, Lubin JH, et al. (1998) Mortality among United States radiologic technologists, 1926-90. Cancer Causes Control 9, 67-75.

16. Freedman DM, Cahoon EK, Rajaraman P, et al. (2013) Sunlight and other determinants of circulating 25-hydroxyvitamin D levels in black and white participants in a nationwide U.S. study. Am J Epidemiol 177, 180-192.

17. Cawthon RM (2002) Telomere measurement by quantitative PCR. Nucleic Acids Res 30, e47.

18. Cawthon RM (2009) Telomere length measurement by a novel monochrome multiplex quantitative PCR method. Nucleic Acids Res 37, e21.

19. Callicott RJ \& Womack JE (2006) Real-time PCR assay for measurement of mouse telomeres. Comp Med 56, 17-22.

20. Simon SL, Preston DL, Linet MS, et al. (2014) Radiation organ doses received in a nationwide cohort of U.S. radiologic technologists: methods and findings. Radiat Res 182, 507-528.

21. Institute of Medicine (2011) Dietary Reference Intakes for Calcium and Vitamin D. Washington, DC: The National Academies Press.

22. Gardner M, Bann D, Wiley L, et al. (2014) Gender and telomere length: systematic review and meta-analysis. ExpGerontol 51, 15-27.

23. Diez Roux AV, Ranjit N, Jenny NS, et al. (2009) Race/ethnicity and telomere length in the multi-ethnic study of atherosclerosis. Aging Cell 8, 251-257.

24. Hunt SC, Chen W, Gardner JP, et al. (2008) Leukocyte telomeres are longer in African Americans than in whites: the national heart, lung, and blood institute family heart study and the Bogalusa Heart Study. Aging cell 7, 451-458.

25. Srikanth P, Chun RF, Hewison M, et al. (2016) Associations of total and free 25OHD and 1,25(OH)D with serum markers of inflammation in older men. Osteoporos Int (epublication ahead of print version 23 February 2016).

26. Zhang Y, Leung DY, Richers BN, et al. (2012) Vitamin D inhibits monocyte/macrophage proinflammatory cytokine production by targeting MAPK phosphatase-1. I Immunol 188, 2127-2135.

27. Fitzpatrick AL, Kronmal RA, Gardner JP, et al. (2007) Leukocyte telomere length and cardiovascular disease in the cardiovascular health study. Am J Epidemiol 165, 14-21.

28. Steer SE, Williams FM, Kato B, et al. (2007) Reduced telomere length in rheumatoid arthritis is independent of disease activity and duration. Ann Rheum Dis 66, 476-480.

29. Valdes AM, Andrew T, Gardner JP, et al. (2005) Obesity, cigarette smoking, and telomere length in women. Lancet 366, 662-664. 